\title{
The Role of Nursing Care in Drug Compliance and Quality of Life in Patients after Coronary Artery "Bypass" Surgery
}

\author{
Besjana Gashi', Vlora Ejupi2, Edonesa Jasiqi', Fitim Gashi2, Eroll Reshtani³, Selami Behluli4, \\ Adelina Ismaili ${ }^{5}$
}

${ }^{1}$ Clinic of Cardiac Surgery and Invasive Cardiology, University Clinical Center of Kosovo, Pristina, Kosovo

${ }^{2}$ Clinic of Hematology, University Clinical Center of Kosovo, Pristina, Kosovo

${ }^{3}$ Health Unit, US Embassy in Kosovo, Pristina, Kosovo

${ }^{4}$ Emergency University Clinical Center of Kosovo and Lecture, College AAB, Pristina, Kosovo

${ }^{5}$ Univesity Clinical of Health Departament of Nursing, College AAB, Pristina, Kosovo

Email: besjana26@hotmail.com, vloraejupi83@hotmail.com, edonesa_gjk@hotmail.com, fitimgashi@hotmail.com, lloreshtani@gmail.com, selamibehluli@hotmail.com, adelina.ismaili3@gmail.com

How to cite this paper: Gashi, B., Ejupi, V., Jasiqi, E., Gashi, F., Reshtani, E., Behluli, S. and Ismaili, A. (2021) The Role of Nursing Care in Drug Compliance and Quality of Life in Patients after Coronary Artery "Bypass" Surgery. Open Journal of Nursing, 11, 331-348.

https://doi.org/10.4236/ojn.2021.115030

Received: March 27, 2021

Accepted: May 23, 2021

Published: May 26, 2021

Copyright $\odot 2021$ by author(s) and Scientific Research Publishing Inc. This work is licensed under the Creative Commons Attribution International License (CC BY 4.0).

http://creativecommons.org/licenses/by/4.0/

(c) (i) Open Access

\begin{abstract}
Cardiovascular disease (CVD) is a broad term that includes a whole range of diseases that affect the heart and blood vessels. Cardiovascular diseases (and not only) or as they are known by the abbreviation (SKV), are as numerous as they are complex, attacking the heart and blood vessels, causing many deaths globally, not to mention, are among the main causes. Arteriosclerosis is diagnosed, mainly on the basis of family and medical history, in which case a physical examination and specific tests are performed, which include: blood tests, Doppler ultrasound, electrocardiogram, chest X-ray, echocardiography, angiography and stress test, etc. The study was conducted at the University Clinical Center of Kosovo (UCCK). The paper is based on data obtained from the research protocol of patients of this clinic, in the period 2016-2018. This study included 100 patients with heart disease and their treatment, with special emphasis on coronary artery bypass grafting. Our goal was to emphasize the care, as well as the quality of life of patients, after coronary artery bypass surgery. This process has always been supervised by the head nurse of the clinic, in order to fully preserve the privacy of the patients included in this research. From the results of this research, we found that males dominate in the number of patients included in the study, age over 50 dominates, and we also found that most patients have relatives who suffer from heart disease. We also see that $18 \%$ of patients continue to smoke after surgery, while $70 \%$ of them stated that their health after surgery is much better than last year, and
\end{abstract}


$84 \%$ of them stated that they use therapy after surgery. Data from another study were performed by the hospital CHF, Self-Care (Self-Care of Heart Failure Index). The results are based on 280 patients, 123 of whom were male and 157 female, their marital status showing that 203 of them were married and that the average age of the patients ranged from 67.2 to 13.4 years. In this study, 147 stated that they had relatives or parents with heart disease, and 133 of them did not. Here we have a difference between the two studies because 79 (29.8\%) patients are smokers out of 280 patients interviewed, so here we have a smaller number of smokers than in our country. While researching elsewhere, most of them emphasized that they value health much more after surgery. With regard to drugs, it was concluded that this example shows that patients who did not have a partner who reminded them to take drugs were less compatible with drugs, compared to those who had a partner or friend. Therefore, in conclusion, we find that the use of drugs after surgery helps to improve the health of patients.

\section{Keywords}

Coronary Bypass, Post-Operative, Nursing Care, Herbicides, Cardiovascular Diseases

\section{Introduction}

Cardiovascular diseases are the most common diseases in the developed world. There has been a steady increase in mortality from cardiovascular causes around the world. It is estimated that in the next 5 years, 1 in 3 deaths will be a consequence of cardiovascular diseases [1]. In particular, the World Health Organization estimates that $88 \%$ of these cases will be reported in low- and middle-income countries and that the prevalence of cardiovascular disease in those countries is growing faster than in high-income countries. Coronary heart disease remains the leading cause of adult morbidity and mortality in Europe and North America [2]. Early detection and prediction of the risk of developing cardiovascular disease is a crucial factor in slowing the growth of cardiovascular mortality worldwide. Coronary artery transplantation is an effective alternative to treating CVD, reducing, preventing acute myocardial infarction (AMI), improving quality of life, and delaying death. Total mortality after CABG according to the literature is estimated at $3.4 \%[3]$.

\subsection{Heart}

The heart is located in the thoracic cage between the two lungs. The heart has the shape of a cone, whose base is oriented up, right and back, while the top (top) is down, left and forward. Four spaces can be seen in the longitudinal section of the heart. The right atrium and left atrium are located at the base of the heart, which are separated by a wall called the interatrial septum. Going from the top, two larger spaces are noticed, the right and the left chamber. They are sepa- 
rated by a wall called the interventricular septum [4]. The cardiovascular system consists of the heart and blood vessels, through which the blood circulates continuously, transporting food and gases. The heart is a hollow muscular organ consisting of two smaller cavities, the kidneys and two larger cavities, chambers, which contract and stretch, forcing blood to circulate. Arteries are elastic blood vessels that carry blood from the heart. Veins are soft elastic vessels that carry blood to the heart. Blood capillaries are the thinnest vessels through which nutrients are exchanged in the blood.

\subsection{Cardiovascular Diseases (CVD)}

Cardiovascular diseases (CVD) are a broad term and include a whole range of diseases that affect the heart and blood vessels. A heart attack or stroke can be the first warning of a serious illness. According to data on diseases of the cardiovascular system, the most common diseases of this group are:

1) Brain diseases-diseases that affect the blood vessels that bring blood to the brain;

2) Congenital heart disease-various congenital malformations of the heart structure;

3) Coronary heart disease-diseases that occur as a result of narrowing of the coronary arteries, the arteries that feed the heart muscle itself;

4) Rheumatic heart disease-diseases of the heart valves and muscles, which have been reported as a result of a rheumatic attack;

5) Peripheral arterial diseases-diseases that affect the blood vessels that bring blood to human limbs;

6) Deep vein thrombosis-is the formation of a thrombus in the deep veins inside the muscles in the body (it can travel to the heart or lungs) [5].

\subsection{Causes of Cardiovascular Disease}

The causes of cardiovascular diseases are different: high blood pressure, chronic infection, chronic inflammation, diabetes, hypothyroidism, obesity, poor diet, nutritional deficiencies, lack of exercise, smoking, genetic predisposition, anxiety, depression, depression, dyslipidemia.

Hypertension: High blood pressure can significantly increase the risk of heart attack and other types of heart disease due to how high blood pressure can damage the walls of the arteries. Often, high blood pressure may be present without any symptoms, making regular blood pressure measurements recommended.

Infections: Chronic infection is another known cause of cardiovascular disease. According to researchers, the primary infectious agents associated with heart disease are: Chlamydia (especially Chlamydia pneumonia, with which $95 \%$ of all people come in contact at some point in their lives).

Diabetes: Diabetics are twice as likely to develop arteriosclerotic vascular disease as non-diabetics. We have two types of diabetes, type I diabetes, which is usually of viral origin, where insulin is no longer produced, and type II diabetes, which can be caused by being overweight, lack of physical activity, in which in- 
sulin is produced but not enough for them, regulate glycemic levels.

Hypothyroidism: Defective thyroid function can contribute to heart disease due to various inequalities created by its hypofunction. Low thyroid function can significantly damage the patient's overall metabolism, as well as adversely affect his pulse and blood pressure, which can result in more severe cardiovascular conditions if the infection is not treated.

Stress: Stimulates the bursting of the hormone catecholamines, which constrict blood vessels and constrict the blood vessels of the heart, which, if also layered with atherosclerotic plaques, can lead to complete closure of the blood vessel, which causes a heart attack [6].

Nutritional deficiencies: Lack of basic nutrients for the body and heart such as vitamins $\mathrm{C}$ and $\mathrm{E}$, coenzyme $\mathrm{K} 10$ (CoK10), magnesium, selenium, essential fatty acids and amino acids such as lysine, contribute to heart disease.

Dyslipidemia: Fats include cholesterol and triglycerides.

The two main components of cholesterol are: LDL cholesterol, which is a harmful component, and a good component called HDL cholesterol, where the latter cleanses the blood of excess cholesterol.

\subsection{Prevention}

Many types of cardiovascular disease can be prevented by managing the risk factors that stimulate them [7]. This is achieved by reducing the use of alcohol and tobacco, eating more fresh fruits and vegetables, reducing salt and sugar levels, as well as not consuming saturated fats, avoiding a passive lifestyle and managing it stress [8]. However, continued exposure to these risk factors may contribute to the development of CVD later in life.

\subsection{Symptoms of Cardiovascular Disease}

The symptoms of cardiovascular disease can often remain hidden and go unnoticed until later stages of the progression of cardiovascular disease. More than half of all heart attack cases have no obvious symptoms before death. Therefore, it is important to investigate the symptoms as early and consistently as possible to avoid risk. The definite symptoms for heart disease are different, depending on the affected categories. It often happened that the patient inherited these diseases from childhood, and in most cases, these pathologies are asymptomatic. However, the patient must be vigilant in some situations such as, climbing stairs, where fatigue and dyspnea are manifested and in these cases there may be chest pain. Even when the patient comes out in a cold environment, chest pain can occur. Common signs that a person is suffering from cardiovascular problems include: dizziness, weakness and pain in the legs while walking, but with withdrawal at rest. Other signs are pain in the chest or neck, which worsens with physical exertion or after eating food, when breathing problems can be reported. Also, the patient feels tired and it is not fatigue that can occur due to lack of sleep or physical work. It is extreme fatigue due to lack of oxygen. Swollen legs 
are a sign of heart problems, a chronic condition in which the heart pumps blood inefficiently. Anxiety, sweating, and nausea are classic symptoms of panic, but they are also indicators of a "heart attack". If these symptoms cause extreme fatigue and are accompanied by pain, you should go to the emergency room immediately [9].

\subsection{Review of Cardiovascular Diseases}

People who show the above signs need to be examined to diagnose their problem. A simple examination is an electrocardiogram (ECG), as well as cardiac ECHO and exercise tests can be used as a diagnostic method, coronary angiography is an invasive examination where coronary arteries can be examined, and those that are narrowed can be located and treated with stenting. (dilation of a blood vessel) or surgery [10].

\subsection{Treatment}

The treatment option that is best for a person will depend on their specific type of cardiovascular disease. However, some options include: drugs such as lowering low-density lipoprotein cholesterol, improving blood flow, or regulating heart rate. Treatment aims to relieve symptoms, reduce the risk of disease recurrence or worsening, and prevent complications such as hospitalization, heart failure, heart attack or death. Depending on the condition, healthcare professionals specializing in providing health care to people with cardiovascular disease may also try to stabilize heart function, reduce blockages, and relax arteries to allow better blood flow [11]. If the drug therapy and hygienic-dietary regime do not stabilize the hemodynamic parameters and the work of the heart, then the patient is referred to the laboratory for cardiac catheterization for cardiac surgery.

\section{Method}

The methodology applied in this paper is based on two components:

These components are: content analysis as well as empirical study of data from different literatures. The research is based on research and was conducted through: literature review and interviews through questionnaires.

The research was conducted through a questionnaire that contained 36 questions and will be applied to 100 patients. The content survey provides questions about the postoperative lifestyle, physical activity, diet, avoiding bad habits, emotional state after the intervention as well as how to use the medication, how much they know about the medications they use. Participants in the sample will be patients who have undergone coronary bypass cardiac surgery, regardless of age or gender.

The people selected for the sample will be in good physical and mental condition to make the survey as realistic as possible. The sample included $100 \mathrm{pa}$ tients, of whom will be patients who underwent intervention at the UCCK in 
Public Cardiac Surgery.

The selected sample was patients who had passed a period of 6 months since cardiac surgery and the survey was conducted individually. All patients were also informed of the purpose of data collection for this study.

In addition to the literature of local and international authors, as well as publications of scientific papers, as well as the most eminent authors in the field, the data presented in the paper are taken from medical protocols of the UCCK clinic, during the period 2016-2018 (from the end of the working day). Diseases, consequently to their state of health after cardiac surgery (drug treatment, diet and exercise), in the Republic of Kosovo-or the University Clinical Center of Kosovo.

\section{Result}

The study included 100 people who underwent cardiac surgery at the Cardiac Surgery Clinic. Of the 100 people surveyed, $40 \%$ were women and $60 \%$ were men (Table 1 and Figure 1).

The study included 100 people who underwent cardiac surgery at the Cardiac Surgery Clinic, $60 \%$ of the subjects were men and the rest were women.

In Figure 2, we presented the age structure of patients who underwent cardiac surgery, and from the cohort of all patients (n 100) the age group of patients from 51 to 60 years dominated.

Figure 3 presents the structure of education of patients who underwent cardiac surgery. Secondary education dominated from the cohort of all patients (n 100).

Table 1. Respondent pol.

\begin{tabular}{cc}
\hline Gender & $\%$ \\
\hline F & 40 \\
M & 60 \\
Total & 100 \\
\hline
\end{tabular}

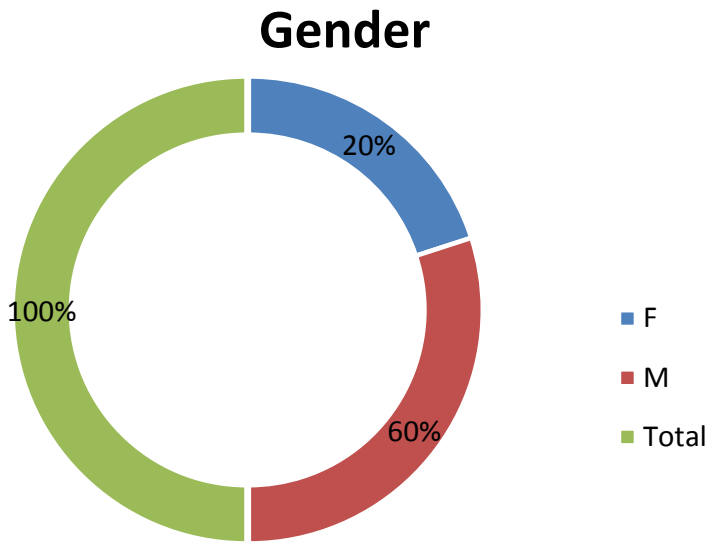

Figure 1. Gender. 


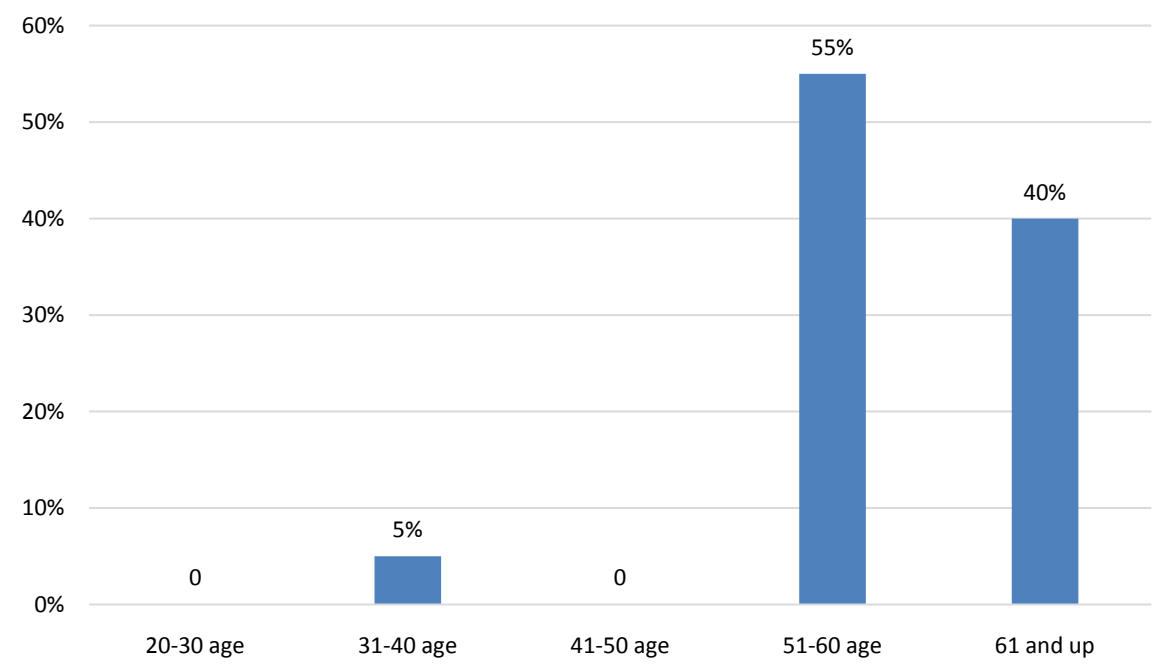

Figure 2. Age patient structure.

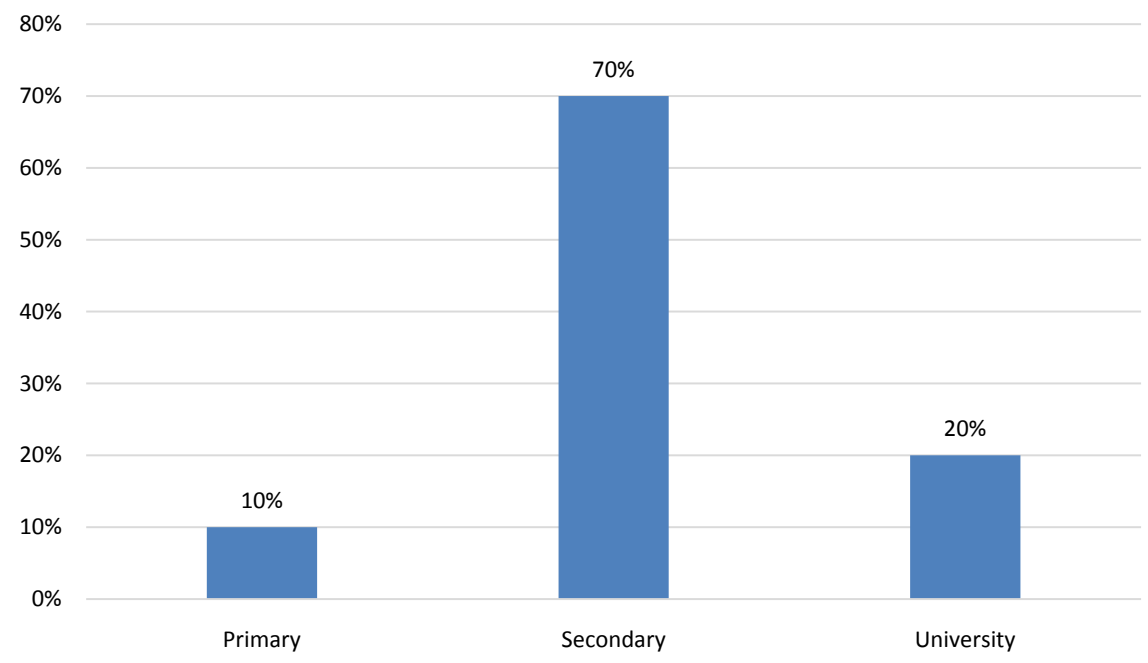

Figure 3. Patient education.

In Figure 4, we presented the employment structure of patients who underwent cardiac surgery. From the cohort of all patients (n 100), a large number of unemployment among patients dominates.

In Figure 5, we present the structure of the residence of patients who underwent cardiac surgery. Of the cohort of all patients (n 100), 60\% were from urban residence, while the rest belonged to rural residence.

\section{Discussion}

The analysis of the data collected during the research enabled the analysis of the impact on compliance with the drugs, after the cardiac surgery of the hospitalized patients at the Clinic for Cardiac Surgery included in this research. Of course, the combination of scientific data with the factual situation in practice is most deserving (conditionally speaking) in reaching an objective conclusion, in the treatment of cardiovascular diseases with special emphasis on coronary artery 


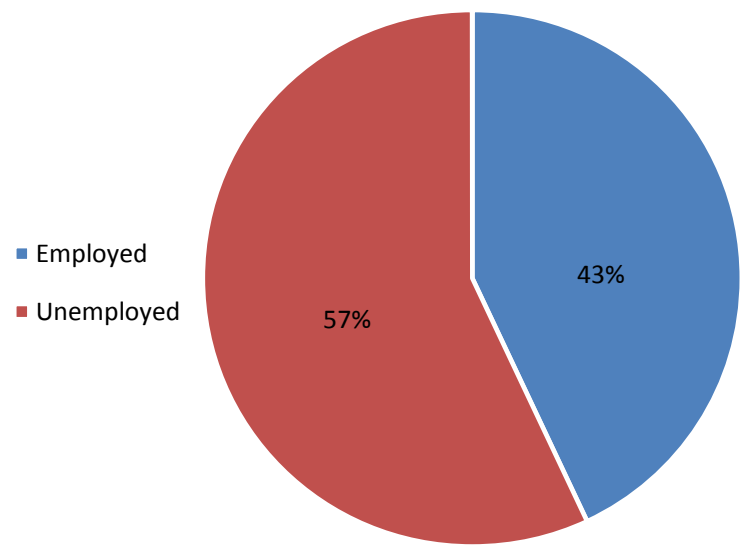

Figure 4. Employment of patients.

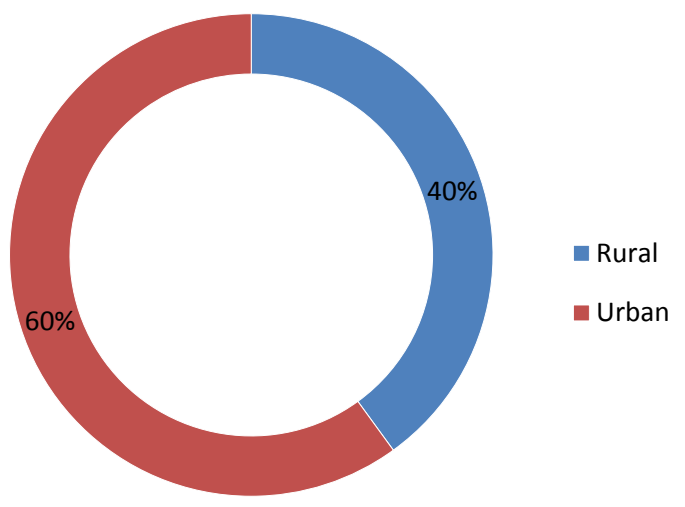

Figure 5. Patient's residence.

transplantation, and above all on the quality of life of postoperative patients. exercise [12]. Of course, the research is based not only on cardiovascular diseases (in the nominal sense of the word), but also on a certain number of patients, their breakdown by age, gender, status, as well as the lifestyle they lead, the meaning regardless of whether they are smokers, they strictly adhere to the consumption of medicines as prescribed by the doctor and other components, which would ensure a better quality, i.e. a healthier life in the future.

The study included 100 people out of 100 people included in the study, 60 were male and the rest were female. The age that participated in this research was over 31 years. In this study, we see that age over 51 is most prevalent. 70 of them have secondary education, and 20 have university education, and the largest number of patients is also unemployed. In the structure inherited from relatives/parents who suffered from heart disease, 76 of them answered that they had relatives or parents, and 24 of them stated that they did not have relatives or relatives suffering from this disease. Overweight was also present in most patients before and after the intervention, and most of them changed their feeding regime after the operation.

Here we conducted a survey of other countries by comparing our country and from this comparison we can see the results achieved. 
In this study, 280 patients were conducted, of which 123 men and 157 women, the comparison between these two studies is that in our country more men were included, while in other countries it is female. Their marital status shows that 203 of them were married, and the average age of the patients ranged from 67.2 to 13.4 years.

In this study, 147 of them stated that they had relatives/parents with heart disease, and 133 of them stated that they did not have family members or relatives with heart disease [13]. While in other studies, most of them emphasized that they assess their health much better after the operation.

Regarding drugs, it was concluded that this example shows that patients who did not have a drug-reminiscent partner were less compatible with the drug, compared to those who had a partner or friend [14].

As for smoking, we can say that 38 smoked before the operation, but not after, 32 smoked but stopped, 18 never smoked, and 12 continue to smoke even after the operation. After the operation, the patient's consciousness is clearly visible. Here I have a difference between the two studies. 79 (29.8\%) patients are tobacco smokers out of 280 patients interviewed, which shows that we have a smaller number of tobacco users here compared to our country [15]. In terms of nerve structure before and after surgery, 69 was confused about surgery, but now he feels full of vitality, as well as a small number who were nervous all the time and continue to be, and none of the patients were nervous at all.

As for exhaustion after surgery, a small number are exhausted before surgery and still feel the same, while most patients are exhausted before surgery, but after surgery I feel much more energetic. Fatigue experienced by patients before and after surgery, 63 stated that they felt a lot of fatigue before surgery but no longer felt after surgery, 35 of them felt that fatigue was partially reduced after surgery, 2 of them stated that they felt tired and continued to feel tired even after surgery. While in the research structure in another country, we see that nervousness was present in the largest number of patients, and they feel much more energetic after the operation [16].

Compared to a year ago, to assess their health now after surgery, 70 of them said they are now much better than last year, 25 of them are now a little better than last year, 5 are almost the same as last year, and none of he did not state that he had more pain than last year. The improvement of the patient's health after the operation is noticeable. In the structure of health research, compared to the current years, a large number of patients now feel much better [17].

In the structure of restrictions on physical activities such as (running, weightlifting and various sports) after surgery, a large number of patients are not limited at all, 37 are slightly limited, 15 stated that they are limited. The body is limited like kneeling or bending after surgery, 54 stated that it is very limited, 32 that it is slightly limited, 14 that it is not limited at all. Regarding various needs, such as bathing or dressing after surgery, 50 stated that they performed the needs without difficulty, 47 that with little difficulty, 3 that with great difficulty. As for walking after the operation, most patients stated that they now walk more than 
before the operation.

A neuropsychological study at the University of Liverpool conducted by the Department of Cardio-Thoracic Surgery on patients after heart surgery (after coronary artery replacement) shows data on their impact on the quality of life reported by patients and on improving mood or improving postoperative physical activity, etc. The quality of physical life associated with health after cardiac surgery was significantly improved in $42 \%$ of patients in the first two months after surgery and in $22 \%$ of other patients in the next 6 months, but the benefit for emotional and social functioning was not so convincing especially in the short term [18].

In the structure with problems with breathing before the operation and whether you still have problems after the operation, most patients had problems, but they were significantly reduced after the operation. In addition to the use of therapy (drugs) after surgery, 84 of them stated that they were affected by drug therapy, and 16 of them that it was not affected. As most of them stated that they knew the names of the medicines, and most of them stated that they had received instructions on the use of medicines. Also the opinion that the drugs they use have high costs, 47 of them stated that they have high costs, 20 of them said that they do not, and 33 of them partially.

In the postoperative sleep notification structure, most postoperative patients slept only in a supine position for several months, and a small number of patients could not adhere to the rules, where they adhered only a month after surgery, and none of them stated that they did not informed of the sleeping position after surgery. Regardless of whether the nurses informed them after cleaning from the hospital about cleaning the wound and who cleaned their wound at home, 75 of them said they were informed and arranged for the nurses to clean the wound, and 25 of them were informed and the wound was cleaned by family members.

How do you generally feel after the operation, 76 stated that they feel very well, 24 of them feel good, and none of them stated that they feel worse than before the operation. Patients' expectations for better health are also high. A large number of eligible patients (No. 107, 73.8\%) claimed to have someone, as opposed to an equally large number of patients (No. 49, 40.8\%) who had no one as a partner or companion to follow the child's plan [19]. The relativity to follow an exercise routine was encountered by (21\%) patients and found to be a significant predictor of noncooperative patients (No. 94 60.2\%) who did not have a partner or friend to perform physical activities [20]. Busy schedule and fear that exercise would worsen heart problems were two factors that were found to have a significant impact on exercise neglect. This example shows that patients who did not have a partner to remember to consume medication were less likely plants, unlike those who had a partner. Therefore, forgetfulness, economic coping, and excessive amounts of herbs have also been identified as significant predictors [21].

The study, conducted in Turkey from January 1, 2001 to January 1, 2003 at the 
Sevket Demirel Heart Center, included 108 patients with coronary bypass over the age of 65, of whom 75 (69.4\%) were male gender [22]. Of the 108 patients, $60 \%$ knew how to use their medication and knew what it was for, while the rest of the patients had family care or nursing supervision.

Overall, studies on quality of life after coronary bypass show results for 3, 6, and 12 months, while knowledge of improving the long-term quality of life of the elderly is limited. Quality of life assessment can be useful for achieving improvements in rehabilitation programs, and evaluation can also document successful therapies, especially from a patient perspective [12] [23].

Various studies have shown that along with poor hygiene and exercise, drug failure is an equally important problem that requires attention. A study conducted over a 12-month period, 2015-2016, approved by the Review Board of the Institute of Health Sciences at Dow University, shows that the prevalence of modifications and drugs after CABG was high, where this poses a major threat to long-term clinical outcome. This study combines three different forces after CABG intervention: medication, diet, and exercise. Patients who encounter drug problems in many cases skip taking it and do not talk to the nurse about it, it seems that another reason that they do not contain prescription drugs is the fear of side effects that the patient has, or even the cost of drugs. Patients must understand that investing in their medications is a necessary task, not just an option, and that the consequences of non-compliance can be serious where they can lead to therapeutic failure [24].

\section{Conclusions}

The groups of patients included in the study were men (60\%), while the most common age group was 51 - 60 years. Of the total sample, $60 \%$ were from urban areas, while according to education, $70 \%$ had secondary education.

Risk factor analysis showed that $77 \%$ of patients were overweight, $70 \%$ of them smoked and $76 \%$ had a positive family history of cardiovascular disease. Out of that, $77 \%$ of the patients changed their hygienic-dietary regime after the intervention and advice on care. The analysis of the quality of life and care presented data that most patients showed improved physical and mental performance after cardiac surgery. Compliance with drugs in research patients is not at the desired level, due to the fact that many parameters were not achieved in accordance with the recommendations. Patients know the names of drugs in $93 \%$ of cases.

The structure of patients who double the dose of the drug after forgetting the dose is $10 \%$ and this shows that they risk their treatment regimen with this action. In $38 \%$ of cases, patients claim that they do not have clear instructions from the medical staff on the use of medication. In $32 \%$ of cases, patients understand and know the instructions for use of drugs, but do not follow them. In $76 \%$ of cases, patients have limited knowledge or do not know the side effects of the medication they are taking. 


\section{Acknowledgements}

From the bottom of my heart, I would like to express my sincere gratitude to all those who supported and encouraged me in conducting this study. First of all, special thanks go to my mentor Shaip Krasniqi, for his care and valuable advice during my study work. The collaboration and ethics of his work were not only an inspiration to me, but also a model worth following.

Specially thanks go to my parents, sisters and brother for their continued support and empathy every minute during these years of study. Thanks also to the company for the love and support they have given me and I will continue to fill my heart to keep going!

\section{Funding}

The study was financed by author.

\section{Conflicts of Interest}

The authors declare no conflicts of interest regarding the publication of this paper.

\section{References}

[1] Peka, L., Neqaj, E., Rustami, D., Bego, A., Imami-Lelqaj, M., Qela, A., Dervishi, V. and Mane, Z.V. (2005) "Infermieristika në specialitete" Tiranë 2005. cap. Sistemi kardiovaskular, angina pectoris fq 45 .

[2] Raqa-Bunjaku, I. Reanimimi kardiopulmunar. cap, Semundjet koronare. fq 24

[3] Serruys, P.W., Morice, M.C., Kappetein, A.P., Colombo, A., Holmes, D.R., Mack, M.J., Ståhle, E., Feldman, T.E., van den Brand, M., Bass, E.J., Van Dyck, N., Leadley, K., Dawkins, K.D., Mohr, F.W. and SYNTAX Investigators (2009) Percutaneous Coronary Intervention versus Coronary-Artery Bypass Grafting for Severe Coronary Artery Disease. New England Journal of Medicine, 360, 961-972. https://doi.org/10.1056/NEJMoa0804626

[4] Sadeghi, M., Ruhafza, H., Shirini, Sh., Akhavan Tabib, A., Aghdak, P. and Hosseini, Sh. (2006) The Prevalence of Coronary Artery Disease According to Rose Questionnaire and ECG: Isfa-han Healthy Heart Program (IHHP). ARYA Journal, 2, 70-74.

[5] Kennedy, J.W., Killip, T., Fisher, L.D., Alderman, E.L., Gillespie, M.J. and Mock, M.B. (1982) The Clinical Spectrum of Coronary Artery Disease and Its Surgical and Medical Management, 1974-1979. The Coronary Artery Surgery study. Circulation, 66, III16-III23.

[6] Kones, R. (2011) Primary Prevention of Coronary Heart Disease: Integration of New Data, Evolving Views, Revised Goals, and Role of Rosuvastatin in Management. A Comprehensive Survey. Drug Design, Development and Therapy, 5, 325-380. https://doi.org/10.2147/DDDT.S14934

[7] Khanji, M.Y., van Waardhuizen, C.N., Bicalho, V.V., Ferket, B.S., Hunink, M.M. and Petersen, S.E. (2018) Lifestyle Advice and Interventions for Cardiovascular Risk Reduction: A Systematic Review of Guidelines. International Journal of Cardiology, 263, 142-151. https://doi.org/10.1016/j.ijcard.2018.02.094

[8] Clark, A.M., Hartling, L. and Vandermeer, B. (2005) Meta-Analysis: Secondary Prevention Programs for Patients with Coronary Artery Disease. Annals of Internal 
Medicine, 143, 659-672. https://doi.org/10.7326/0003-4819-143-9-200511010-00010

[9] Fauci, A.S., Braunwald, E., Kasper, D.L., Hauser, S.L., Longo, D.L. and Jameson, J.L. and Loscalizo, J. (2014) Parimet e Mjekësisë Interne Harrison. McGraw-Hill, New York.

[10] Sampalis, J., Boukas, S., Liberman, M., Reid, T. and Dupuis, G. (2001) Impact of Waiting Time on the Quality of Life of Patients Awaiting Coronary Artery Bypass Grafting. Canadian Medical Association Journal, 165, 429-433.

[11] Khan, J.H., Magnetti, S., Davis, E. and Zhang, J. (2000) Late Outcomes of Open Heart Surgery in Patients 70 Years or Older. The Annals of Thoracic Surgery, 69, 165-70. https://doi.org/10.1016/S0003-4975(99)01185-6

[12] Kjellgren, K.I., Ahlner, J. and Säljö, R. (1995) Taking Antihypertensive Medication-Controlling or Co-Operating with Patients? International Journal of Cardiology, 47, 257-268. https://doi.org/10.1016/0167-5273(94)02203-U

[13] Eagle, K.A., Guyton, R.A., Davidoff, R., Edwards, F.H., Ewy, G.A., Gardner, T.J., et al. (2004) ACC/AHA 2004 Guideline Update for Coronary Artery Bypass Graft Surgery: A Report of the American College of Cardiology/American Heart Association Task Force on Practice Guidelines (Committee to Update the 1999 Guidelines for Coronary Artery Bypass Graft Surgery). Circulation, 110, 1168-1176. https://doi.org/10.1161/01.CIR.0000138790.14877.7D

[14] Cupples, S.A. (1991) Effects of Timing and Reinforcement of Preoperative Education on Knowledge and Recovery of Patients Having Coronary Artery Bypass Surgery. Heart Lung, 20, 654-660.

[15] Herdy, A.H., Marcchi, P.L., Vila, A., Tavares, C., Collaço, J., Niebauer, J. and Ribeiro, J.P. (2008) Pre- and Postoperative Cardiopulmonary Rehabilitation in Hospitalized Patients Undergoing Coronary Artery Bypass Surgery: A Randomized Controlled Trial. American Journal of Physical Medicine \& Rehabilitation, 87, 714-719. https://doi.org/10.1097/PHM.0b013e3181839152

[16] Khanderia, U., Townsend, K.A., Erickson, S.R., Vlasnik, J., Prager, R.L. and Eagle, K.A. (2008) Medication Adherence Following Coronary Artery Bypass Graft Surgery: Assessment of Beliefs and Attitudes. Annals of Pharmacotherapy, 42, 192-199. https://doi.org/10.1345\%2Faph.1K497

[17] Ho, P.M., Magid, D.J., Shetterly, S.M., Olson, K.L., Maddox, T.M., Peterson, P.N., Masoudi, F.A. and Rumsfeld, J.S. (2008) Medication Nonadherence Is Associated with a Broad Range of Adverse Outcomes in Patients with Coronary Artery Disease. American Heart Journal, 155, 772-779. https://doi.org/10.1016/j.ahj.2007.12.011

[18] Newman, M.F., Kirchner, J.L., Phillips-Bute, B., Gaver, V., Grocott, H., Jones, R.H., et al. (2001) Longitudinal Assessment of Neurocognitive Function after Coronary-Artery Bypass Surgery. New England Journal of Medicine, 344, 395-402. https://doi.org/10.1056/NEJM200102083440601

[19] da Costa Torres, D., dos Santos, P.M., Reis, H.J., Paisani, D.M. and Chiavegato, L.D. (2016) Effectiveness of an Early Mobilization Program on Functional Capacity after Coronary Artery Bypass Surgery: A Randomized Controlled Trial Protocol. SAGE Open Medicine, 4, Article ID: 2050312116682256.

https://doi.org/10.1177\%2F2050312116682256

[20] Aldea, G.S., Gaudiani, J.M., Shapira, O.M., Jacobs, A.K., Weinberg, J., Cupples, A.L., Lazar, H.L. and Shemin, R.J. (1999) Effect of Gender on Postoperative Outcomes and Hospital Stays after Coronary Artery Bypass Grafting. The Annals of Thoracic Surgery, 67, 1097-1103. https://doi.org/10.1016/S0003-4975(99)00055-7 
[21] Walsh, B.W., Schiff, I., Rosner, B., Greenberg, L., Ravnikar, V. and Sacks, F.M. (1991) Effects of Postmenopausal Estrogen Replacement on the Concentrations and Metabolism of Plasma Lipoproteins. New England Journal of Medicine, 325, 1196-1204. https://doi.org/10.1056/NEJM199110243251702

[22] Guler, C. (1997) Aging as a Public Issue. In Geriatrics, Ankara, 7. (In Turkish)

[23] Ware, J.E. (1997) Introduction. In SF-36 Health Survey Manual and Interpretation Guide, Medical Outcome Trust, Boston, 2:3.

[24] Blasberg, J.D., Schwartz, G.S. and Balaram, S.K. (2011) The Role of Gender in Coronary Surgery. European Journal of Cardio- Thoracic Surgery, 40, 715-721. https://doi.org/10.1016/j.ejcts.2011.01.003 


\section{Questionnaire}

1) Do you have relatives/parents who have suffered from heart disease?

a) Yes

b) No

2) Have you had problems with being overweight before surgery and has this problem been fixed now after surgery?

a) I was overweight, but I wasn't anymore.

b) I still have problems with being overweight.

c) Even before the operation, I had no problems with excess weight.

3) Did the diet change surgically before the operation?

a) Yes, it has changed, now use vegetable-based dishes (food, salad).

b) No, it hasn't changed, I still use dough-based dishes, fast food and meat.

4) Have you been and are you still a smoker?

a) I've never been a smoker.

b) I smoked, but quit years ago.

c) I smoked before the operation, but not after.

d) I still smoke after the operation.

5) Were you a very nervous person before the operation and do you feel calmer now after the operation?

a) I was nervous all the time and still am.

b) I was confused about the operation, but now I feel full of life.

c) At no point was I nervous.

6) Did you feel exhausted before the surgery and did your energy increase after the surgery?

a) I was exhausted before the operation and I still feel the same.

b) In a small part of the time, I still feel exhausted.

c) I was, but after the operation I feel much more energetic.

7) How do you describe your fatigue before and after surgery?

a) I felt tired and I feel tired even after the operation.

b) Fatigue is partially reduced after surgery.

c) Before the operation, I felt very tired, but after the operation, I don't feel it anymore.

8) Compared to a year ago, how would you rate your health now after surgery?

a) Much better now than last year

b) Something better now than last year

c) Almost the same as last year

d) Much worse than last year

9) Are physical activities like (running, heavy lifting and various sports) limited after surgery?

a) Yes, they are very limited.

b) Yes, they are a bit limited.

c) No, they are not limited at all. 
10) Are the climbs on the ladder rope limited after the operation?
a) Yes, they are very limited.
b) Yes, they are a bit limited.
c) No, they are not limited at all.

11) Is body movement limited, such as kneeling or bending after surgery?

a) Yes, it is very limited.

b) Yes, it's a bit limited.

c) No, it is not limited at all.

12) Do you bathe or dress after surgery?
a) Yes, with great difficulty.
b) Yes, with some difficulty.
c) No, there are no difficulties at all.

13) Do you go for regular walks after surgery?
a) Yes, more than before the operation.
b) Yes, less than before the operation.
c) I don't go for a walk at all.

14) How much do you walk during the day after surgery?
a) Up to $1 \mathrm{~km}$ of outdoor walks every day.
b) I usually walk until I feel tired.
c) Very rarely in shorter relationships.

15) Did you have breathing problems before the operation and do you still have it after the operation?
a) Yes, breathing problems are almost the same.
b) Yes, I had a problem, but they were significantly reduced after the surgery.
c) I did not have such pronounced breathing problems before the operation, but they got worse after the operation.

16) How many emotional health problems have you had during the last 6 months during social activities such as (visiting friends, etc.)?
a) All the time
b) Most of the time
c) A small part of the time
d) For a short time

17) Have you had any physical pain during the last 6 months after the surgery?
a) Nothing
b) A little
c) On average
d) Many

18) Do you use therapy (drugs) after surgery?
a) Yes
b) No

19) Do you think that you use a lot of medication after the operation?
a) Yes a lot. 
b) Do not use two or three types of medication.

c) No, there are not many of them if they are for the good of my health.

20) Do you know what medications you are using?

a) Yes, for concomitant diseases (hypertension, diabetes, etc.).

b) Yes, they are drugs for normal protection of blood, pulse, fat values.

c) No, but I still use it.

d) I don't use them.

21) Do you know the names of the medications you use?

a) Yes

b) No

22) If you forget to take your medication during a meal, what is the next action?

a) Use double the dose in the following schedule.

b) Use them as soon as I remember.

c) I continue the tablet in the following schedule without doubling the dose.

23) Did you receive any instructions on the use of the medication when you were released from the hospital?
a) Yes, and they were very clear.
b) Yes, but they weren't very clear.
c) No, I did not receive medication instructions

24) Did you follow the instructions for use of the drug?
a) Yes
b) No
c) Partially

25) Do you look at the expiration date before using the medication?
a) Yes
b) No

26) Have you used medications other than those prescribed?
a) Yes
b) No

27) Did you get information and do you know the side effects you have from the medications you use?
a) Yes
b) No
c) Partially

28) Do you know them and how do you distribute drugs?
a) According to the name of the drug.
b) I know them based on the color and size of the tablets.
c) Use separate medicine boxes.

29) Does anyone help you with medications when and how much to use?
a) No, I don't need help.
b) Yes, my family helps me.

30) Do you think that the drugs you use have a high price?

a) Yes 
b) No

c) Partially

31) Do you think that the medications you use have improved your health after the operation?
a) Yes
b) No
c) Partially

32) Are you informed about the sleeping position after the operation?

a) Yes, after the operation I slept only a few months in a lying position.

b) Yes, but I could not follow the rules where I followed only a month after the operation.

c) No, I was not informed.

33) Were you informed about how the nurse cleaned the wound after discharge from the hospital and who cleaned your wound at home?

a) Yes, I was informed and I arranged for the nurses to clean the wound.

b) Yes, they were informed and the wound was cleaned by family members.

34) Did the nurse inform you about the instructions (breathing exercises, diet, importance of physical activity) after discharge from the hospital?
a) Yes
b) No

35) How do you generally feel after the operation?

a) Very good

b) Good

c) Worse than before surgery

36) How well have your postoperative health expectations been met and do you think the surgery has paid off to improve your quality of life? (51)

a) Expectations were met, my health improved a lot.

b) Yes, the operation paid off, but not all expectations were met.

c) No, it's not worth it, my health has deteriorated. 